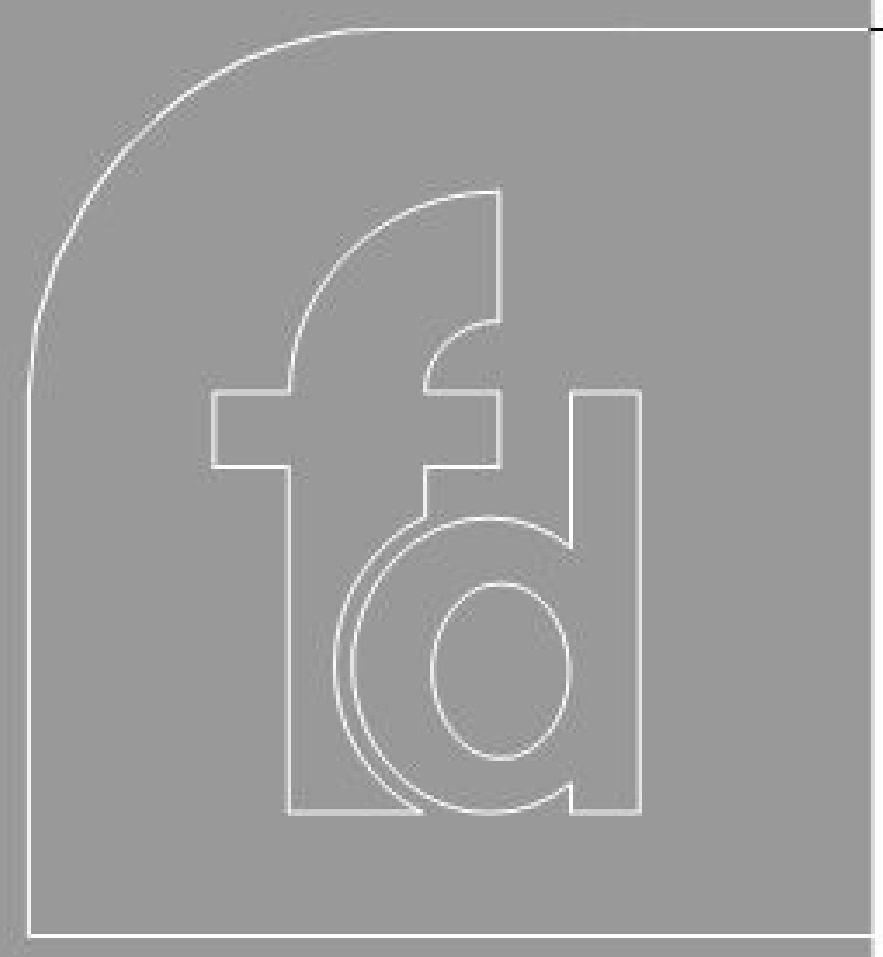

\section{CONTENTS \\ Transmission \\ Clinical manifestations \\ Laboratory diagnosis \\ Treatment}

Experimental leishmaniasis

Vaccines

Expert opinion \&

five year view

Key issues

References

Affiliations

\author{
${ }^{\dagger}$ Author for correspondence: \\ Chief of Laboratory of \\ Immunoregulation, Centro de \\ Pesquisa Goncalo Moniz-Fundacao \\ do Instituto Oswaldo Cruz- \\ Salvador Bahia Brazil, \\ Tel.: +55713568782 , Ext. 211 \\ Fax: +55713568782 , Ext. 269

\section{KEYWORDS:} \\ co stimulatory molecules, \\ cytokines, immunoregulation, \\ IVP, Leishmania, leishmaniasis, \\ sand fly, vaccine
}

\title{
Vaccines in leishmaniasis: advances in the last five years
}

\author{
Cláudia Brodskyn, Camila I de Oliveira, Aldina Barral and \\ Manoel Barral-Netto ${ }^{\dagger}$
}

The leishmaniases are a group of diseases caused by protozoa of the genus Leishmania which affects millions of people worldwide. The leishmaniases are transmitted to the vertebrate hosts by phlebotomine sand flies. In this review, we focus on clinical aspects of the leishmaniases and on the immune response against the parasite, both in animal models and humans. These aspects are of key importance to understand the many attempts to obtain an effective vaccine against Leishmania. We considered the last advances in new generation vaccines, including the use of new adjuvants to improve the protective response against the parasite. Finally, the possibility to use components of the sand fly saliva as part of vaccines against the infection by Leishmania is mentioned.

Expert Rev. Vaccines 2(5), 705-717 (2003)

The leishmaniases represent endemic infections occurring in various regions of the world but predominantly in the tropical and subtropical regions. Outbreaks are often registered during deforestation or incursions into forests. Leishma niases are transmitted by different species of blood sucking phlebotomines (sand flies). Cur rently, the leishmaniases, prevalent in four conti nents, are considered to be endemic in 88 coun tries, 72 of which are developing countries: $90 \%$ of all visceral leishmaniasis cases occur in Bangla desh, Brazil, India, Nepal and Sudan; $90 \%$ of mucocutaneous leishmaniasis occur in Bolivia, Brazil and Peru; $90 \%$ of cutaneous leishmaniasis cases occur in Afghanistan, Brazil, Iran, Peru, Saudi Arabia and Syria

Leishmaniases present a wide spectrum of clinical manifestations, with either tegumentary or visceral involvement. The infection may be visceral, as in visceral leishmaniasis (VL) or kala azar, restricted to the skin, as with the chronic ulcer of Oriental sore, or may spread to mucosae to cause the disfiguring espundia. Tegumentary leishmaniasis ranges from localized cutaneous and mucocutaneous leishmaniases (CL and $\mathrm{MCL}$ ), representing the responsive pole, to dif fuse cutaneous leishmaniasis (DCL), represent ing the unresponsive pole. VL ranges from sub clinical to fatal disease. All these different clinical presentations are caused by otherwise morphologically similar Leishmania species [1].

The parasites that cause New World CL and MCL are grouped under the Leishmania braziliensis and L. mexicana complexes. L. tropica, $L$. aethiopica and $L$. major represent the etiological agents of the Old World CL.

Parasites from the $L$. donovani complex are responsible for VL cases in both the Old and New Worlds. $L$. donovani from the Americas is also designated $L$. infantum .

\section{Transmission}

The leishmaniases are transmitted by the bite of infected female phlebotomine sand flies, pri marily infected by animal reservoir hosts. Humans are also a reservoir for some forms of the disease. The life cycle begins when an infected female sand fly takes a blood meal from a human host. As the sand fly feeds, Leishmania metacyclic promastigotes enter the vertebrate host via the proboscis.

Within the human host, the metacyclics are phagocytosed by macrophages where they differ entiate into amastigote forms, which reproduce by binary fission. They increase in number until the infected cell eventually bursts releasing para sites able to infect other phagocyctic cells. When the infected host is bitten by another female sand fly, parasites are picked up by the fly and the life cycle continues. 


\section{Clinical manifestations}

It is often assumed that the type of disease is determined by the species of parasite but actually this is an oversimplification. The genetics and immunocompetence of the host may be equally important for some parasite species.

\section{Tegumentary leishmaniasis}

Cutaneous lesions begin at the site of parasite entrance as a small papule which develops into a nodule that ulcerates in the center. The incubation period ranges from 2 weeks to several months (reviewed in [1]). The initial lesion generally transforms into an indolent ulcer. The most frequent aspect observed in CL cases is a single ulcer with elevated borders and a sharp crater. In around $1 \%$ of cases, due to hematogenous spread, a pattern of disseminated CL can be observed, sometimes with more than 700 small ulcer ated lesions in a patient. Disseminated CL is completely different from diffuse CL, a rare entity in which many lesions are also observed but in which the lesions are nodular and nonulcerated.

Mucosal involvement, a characteristic of MCL occurs in less than $3 \%$ of patients infected with $L$. braziliensis (reviewed in [1]. Patients with multiple or extensive skin lesions above the waistline and inadequate therapy of the primary lesion are at higher risk of developing MCL. Mucosal lesions occur a few weeks to many years after the onset of infection. Usually, this type of involvement begins in the nasal mucosa but the disease can spread to the hard and soft palate, uvula, pharynx, gums and upper lip and may cause extensive destruction of the nasal septum.

The cutaneous lesions of Old World leishmaniasis cause much less harm than those of the New World. Between 90 and $95 \%$ of these lesions heal spontane ously and only rarely cause a mutilated aspect. L. tropica is responsible for the 'dry' type of disease, characterized by lesions in exposed areas as single or mul tiple soft red papules. L. major produces the rural 'wet' type of disease. The lesions are larger, multiple in $80 \%$ of the cases and display a strong tendency towards central necrosis producing a hemorrhagic crust. The lesions show progressive flattening and complete spontaneous healing, frequently within a few months, leaving a fibrotic scar. Lesions caused by L. aethiopica are usu ally single, appearing as reddish plaques, generally with a shallow ulcer in the center and papular elements in the neighborhood. With few exceptions, the infection confers lifelong immunity.

\section{Visceral leishmaniasis}

The incubation period of VL is estimated to range from 2 to 4 months. The disease may present an acute, subacute or chronic evolution but most infected individuals remain completely asymptomatic (reviewed in [1]). The onset of disease is generally insidious but less frequently it manifests abruptly, with a fatal outcome within a few weeks. The subacute form of disease gen erally occurs in children as well as the very severe form, evolving to death. The chronic form has a prolonged course, frequently presenting remissions (reviewed in [1]).

The asymptomatic form (latent infection) is characterized by a positive serology and normal physical examination. Some of these infected individuals present a positive intradermal test. Infected individuals may evolve to a subclinical form of VL or directly to an overt form of disease (classical VL). The classical manifestations of VL are fever, cough, weight loss, weakness, diarrhea or dysentery and abdominal swelling. Patients also present with anemia, edema, bleeding episodes and huge hepat osplenomegaly. Association with conditions that cause imunos supression can lead to progression from an asymptomatic form to the classical disease.

\section{Leishmania/HIV coinfection}

Leishmania/HIV coinfection is emerging as an extremely seri ous, new disease and coinfections are being reported more fre quently in various parts of the world. It is anticipated that the number of Leishmania/HIV coinfections will continue to rise in the coming years and there are indications that cases are no longer restricted to endemic areas. The overlapping geographi cal distribution of VL and AIDS is increasing due to two main factors: the spread of the AIDS pandemic in suburban and rural areas of the world and the simultaneous spread of VL from rural to suburban areas.

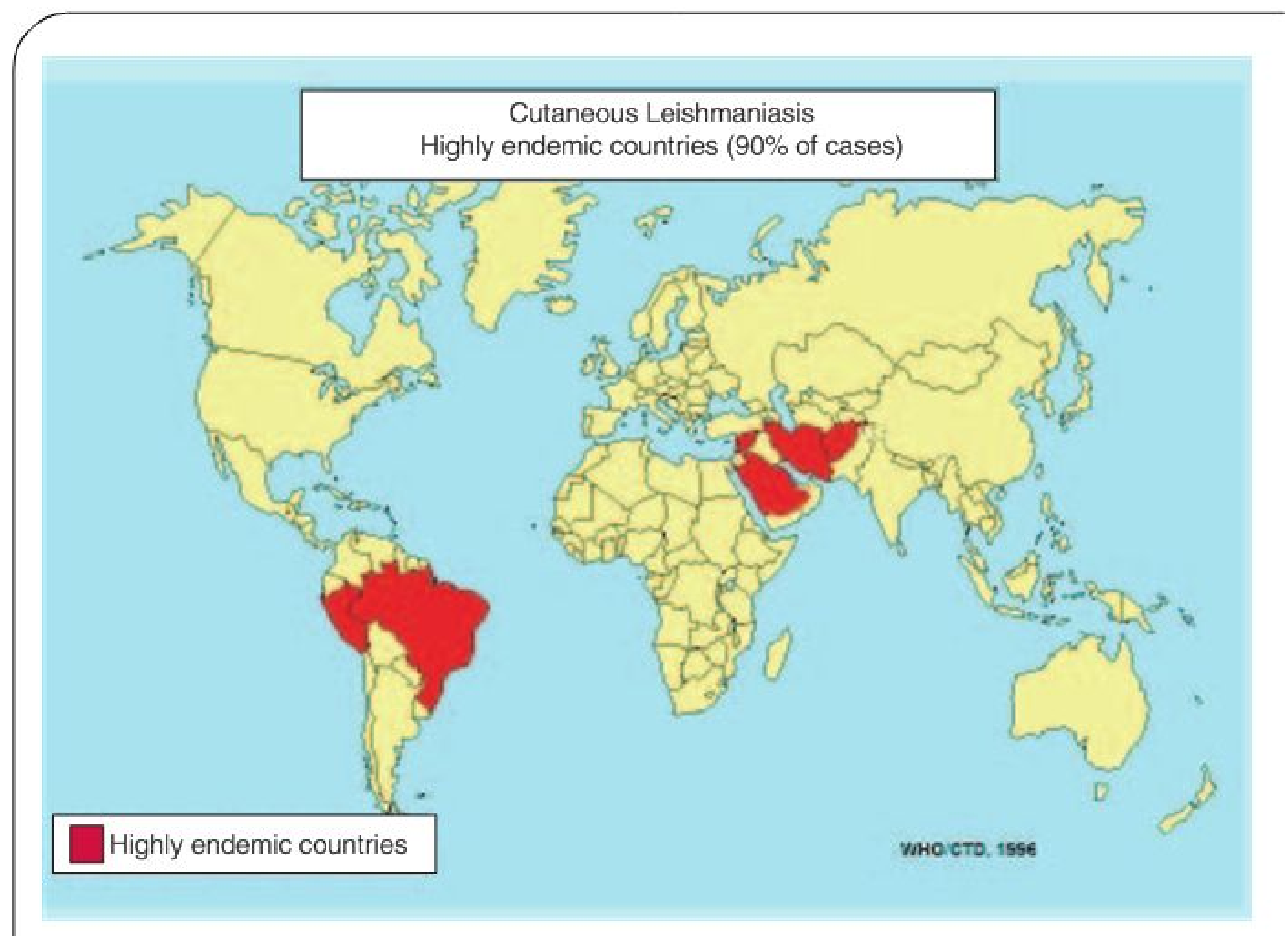

Figure 1. Global distribution of reported cases of cutaneous leishmaniasis, as examined by the world health organization (WHO) [101]. 
Table 1. Clinical characterisitics of human leishmaniasis.

\begin{tabular}{|c|c|c|c|c|}
\hline Characteristic & Mucocutaneous & Cutaneous & Diffuse & Visceral \\
\hline Lesions & $\begin{array}{l}\text { Ulcerative destruction of } \\
\text { the nasal septum }\end{array}$ & $\begin{array}{l}\text { Single, occasionally a } \\
\text { small number, ulcerated } \\
\text { lesion with elevated } \\
\text { borders and necrotic } \\
\text { center }\end{array}$ & $\begin{array}{l}\text { Nonulcerated nodules } \\
\text { spread through different } \\
\text { areas of the body }\end{array}$ & Internal organs \\
\hline $\begin{array}{l}\text { Histopathology and parasite } \\
\text { numbers }\end{array}$ & $\begin{array}{l}\text { Granulomatous reactions } \\
\text { with very few parasites }\end{array}$ & $\begin{array}{l}\text { Chronic inflammatory } \\
\text { responses with moderate } \\
\text { number of parasites }\end{array}$ & $\begin{array}{l}\text { Monotonous macrophagic } \\
\text { infiltration with abundant } \\
\text { parasites }\end{array}$ & $\begin{array}{l}\text { Marked macrophagic } \\
\text { proliferation with heavy } \\
\text { parasitism in the } \\
\text { hematopoietic organs }\end{array}$ \\
\hline $\begin{array}{l}\text { Anti Leishmania antibody } \\
\text { levels }\end{array}$ & Low & Low & Moderate to high & High \\
\hline $\begin{array}{l}\text { Anti Leishmania } \mathrm{CMl} \text { (in } \\
\text { vitro and in vivo tests) }\end{array}$ & Strongly positive & Positive & Negative & Negative \\
\hline
\end{tabular}

CMl: Cell mediated immunity.

AIDS and VL aggravate each other. VL accelerates the onset of AIDS and shortens the life expectancy of HIV infected people and AIDS increases the risk of VL by 100-1000 times in endemic areas. VL is considered a major contributor to a fatal outcome in co infected patients. Leish maniasis can be transmitted directly from person to person through the sharing of needles, and intravenous drug users are the main population at risk for coinfection.

\section{Laboratory diagnosis}

Routine diagnosis is made by direct examination of smears, his topathological examinations of lesions, serological tests or skin testing with Leishmania antigen (Montenegro's reaction). A definitive diagnosis depends on the identification of amastig otes in tissue or isolation of promastigote in culture. Antileish manial antibodies are present in the serum of patients with CL as detected by ELISA or immunofluorescence, direct agglutina tion or other assays [2]. The Montenegro skin test is positive in only $51.6 \%$ of cases of L. amazonensis infection, whereas a pos itivity of $87 \%$ is observed in infections with other species of Leishmania (reviewed in [1]).

The polymerase chain reaction (PCR) offers several advan tages over the previously described methods, in the sense that it can be more sensitive, more specific and, most importantly, more rapid than the above mentioned methods. A number of PCR assays have been described for the detection and charac terization of Leishmania parasites [3,4]. These assays target the amplification of kinetoplast DNA (kDNA), rRNA, miniexon genes and nuclear DNA sequences. These methods present varying specificities: some identify the parasite to the species complex whereas others will identify all Leishmania species. This information is sufficient for diagnostic purposes; how ever, higher resolution can contribute directly to understand ing the epidemiology of leishmaniasis. PCR is particularly useful in the case of CL because of the requirement of parasi tological confirmation for definite diagnosis and because of the low sensitivities of currently used methods. In the case of cutaneous leishmaniasis due to L. braziliensis, the scarcity of parasites in the lesion makes parasitological confirmation rather difficult. This may lead to misdiagnosis and a delay in starting the treatment, which is especially concerning since L. braziliensis parasites have a tendency to metastasize to the mucosal areas. Early detection can prevent these cases allow ing the implementation of the specific treatment to patients in areas where L. braziliensis is prevalent.

In this sense, we have investigated the use of the PCR as a diagnostic tool in an area endemic for L. braziliensis. We have found the PCR to be $100 \%$ sensitive since it was able to detect parasite DNA in all biopsies from patients infected with Leishmania. Furthermore, samples from healthy individuals, residing at the endemic area with a positive Montenegro skin test were also negative when tested for the presence of parasite DNA (DE OLIVEIRA, IN PRESS). These results reinforce the specificity of the PCR since it only detects cases of active infection. These results are in agreement with other reports in the literature and, collec tively, suggest that the PCR could be employed as a routine diagnostic tool.

\section{Treatment}

Pentavalent antimony containing drugs (sodium stibogluco nate and meglumine antimoniate [Glucantime, Aventis, NJ, USA]) are the first choice for leishmaniasis treatment. Amphotericin B is an alternative for patients who fail to respond to pentavalent antimony.

Both antimonials and amphotericin exhibit frequent side effects, which should be taken in account by the physician responsible for the treatment.

In the mouse model, chemotherapy is ineffective in the absence of $\mathrm{T}$ cells responses $[5,6]$. These findings highlight the importance of searching effective immunopreventive an/or immunotherapeu tic approaches against leishmaniasis and that these approaches may find use even when combined to pharmacological products [7]. 


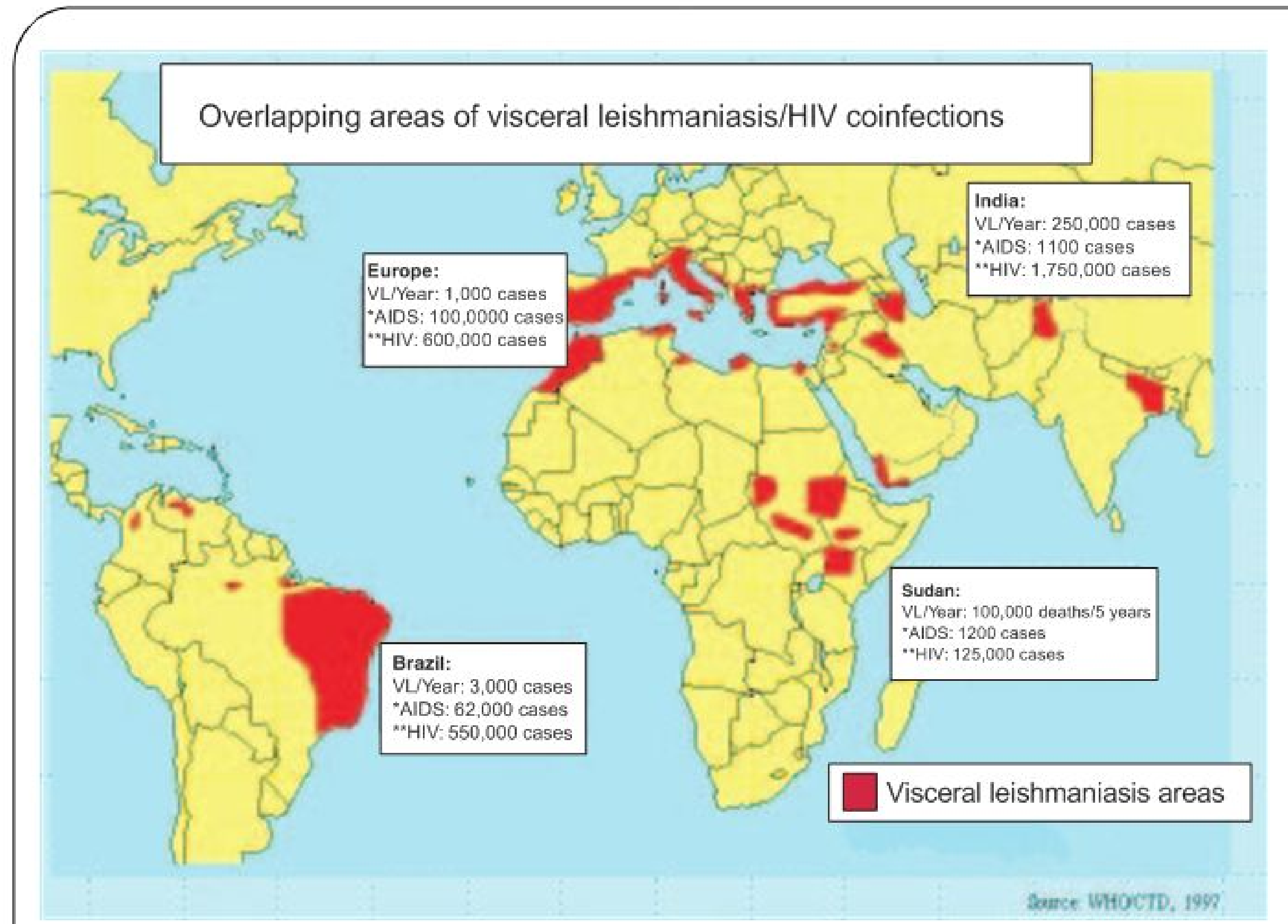

Figure 2. Global distribution areas of leishmaniasis and Leishmania/HIV coinfection, 1990-1998, as examined by the WHO [101].

development of a Th1 response. Th2 cytokines lead to the development of severe lesions in mice infected by $L$. major, probably by deactivating infected cells. The production of reactive nitrogen intermediates by IFN $\gamma$ activated macro phages is inhibited by transforming growth factor (TGF) $\beta$, IL 4, IL 13, IL 10 [10]. The downregulation of Th2 cytokines might be crucial for the development of acquired resistance.

In correlation, there is also support for the need of IL 12 to redirect the early Th2 response. A downregulation of IL 12 receptor $\beta 2$ chain (IL 12R) $\beta 2$ may be responsible for the defective IL 12 response in $\mathrm{BALB} / \mathrm{c}$ mice [11], which could explain the high susceptibility of $\mathrm{BALB} / \mathrm{c}$ mice to L. major. The relevance of this process has been questioned, since $\mathrm{BALB} / \mathrm{c}$ mice expressing an IL $12 \mathrm{R} \beta 2$ transgene maintain a susceptible pheno type, despite stable IL 12 signaling and activation of STAT4 [12]. Therefore, the

\section{Experimental leishmaniasis}

\section{Tegumentary leishmaniasis}

Following inoculation into the skin, the flagellated promastigote penetrates into the macrophage, transforms into amastigotes and multiplies. The infected macrophage exhibits leishmani cidal activity as shown by its increased capacity to produce toxic oxygen and nitrogen radicals in response to interferon (IFN) $\gamma$.

Several experimental models of leishmaniasis have been developed and infection of mice by L. major is one of the best studied models. The mouse model reproduces many aspects of the human disease, including a range of susceptibility states depending on the strain of mouse used. BALB/c mice are highly susceptible, upon infection they develop large skin ulcers, which expand and metastasize, leading to death. On the other hand, C57BL/6 and CBA/N are resistant, they develop small lesions, which cure in 10 to 12 weeks and are resistant to reinfection. Most other strains show intermediate susceptibili ties. The relevance of the T helper (Th) 1 or 2 balance to the regulation of outcome disease in vivo was demonstrated in sev eral reports. Resistance has been thought to be linked to a Th1 response, with production of interleukin (IL) 12 and IFN $\gamma$, whereas susceptibility has been related to a predominant Th2 response determined by the presence of IL 4. Recent data, however, revealed a more complex picture.

The necessity to inhibit Th2 cytokine production in order to obtain a murine resistant genotype has been demonstrated using transgenic mice with a resistant background constitu tively expressing IL 4 (for review [8]) or IL 10 [9]. These mice fail to control L. major infection, although they present a strong Th1 response. Therefore, the sustained production of Th2 cytokines leads to susceptibility, in spite of not precluding the susceptibility or resistance of different strains of mice to infec tion by L. major depends on multiple factors. Among them, the inflammatory or tissue environment in which the early Th2 response is induced might be important to the outcome of infection. For instance, the presence of neutrophils, present in the inflammatory infiltrate for several weeks in the BALB/c footpad, might contribute to the sustained induction of Th2 response because the depletion of neutrophils at the time of $L$. major inoculation in BALB/c inhibits IL 4 response and pro motes partial resistance [13]. Another factor that contributes to the susceptibility of BALB/c mice is the existence of different populations of dendritic cells (DCs) with the capacity to induce preferentially $\mathrm{Th} 1$ or $\mathrm{Th} 2$ cells. Such populations are probably not distinct APC lineages but the result of distinct modulation by cytokines or chemokines present in specific tissue environ ment [14]. Skin DCs from both resistant C57BL/6 and suscepti ble BALB/c mice release IL 12 when infected with L. major [15]. Recently, it has been shown that IL $1 \alpha$ administration resulted in increased Th1 and decreased Th 2 cytokine production. IL $1 \alpha$ and IL 12 treatments were similarly effective and the IL $1 \alpha$ efficacy was strictly IL 12 dependent. These data indicate that local administration of IL $1 \alpha$ acts in conjunction with IL 12 influencing Th development in cutaneous leishmaniasis [16, 17]. On the other hand, disease outcome may not be defined by cytokine production only. Although BALB/c and B10.D2 mice have the same major histocompatability complex (MHC) phe notype ( $\mathrm{H} 2 \mathrm{~d}$ ), their $\mathrm{DC} 1 \mathrm{bb}^{+}$differ in the ability to polarize naive $\mathrm{T}$ cells into either Th1 or Th2 effector cells. This differ ence is cell intrinsic; is not restricted to MHC haplotype and is observed with both parasite specific and allospecific CD4 $\mathrm{T}$ cells [18]. 
Interactions between costimulatory molecules and their receptors (CTLA 4/CD28 B7 and OX 40 OX40L) may influ ence the development of Th2 responses to the parasite in vivo (for review, [8]), suggesting the differential expression of these molecules on distinct subsets of APCs in different tissues.

Although an early $\mathrm{Th} 2$ response may not be a crucial event in the development of a nonhealing phenotype in BALB/c mice, there is little doubt that a sustained $\mathrm{Th} 2$ response is responsible for the outcome of infection. Recently, the importance of IL 13 in the mechanism of sustaining a Th2 response has been dem onstrated [19]. Some cytokines may alter the course of the disease without changing the Th1 or Th2 cytokine pattern.

Treatment of $\mathrm{C} 57 \mathrm{BL} / 6$ crossed BALB/c F1 mice with anti bodies against TGF $\beta$ enhanced the resistance to $L$. major. This treatment did not alter IL 4 or IFN $\gamma$ production but increased the production of nitric oxide by macrophages in parasitized lesions [20].

There is also ample support for the concept of inflammatory type 1 cytokines as mediators of protection. Genetic ablation of molecules in vivo linked to Th1 development, such as IL 12, IFN $\gamma$ and TNF $\alpha$, IFN $\gamma$ R, transcription factors (T bet and STAT4) or costimulatory molecules (CD40 CD40L) leads to sus ceptibility to $L$. major [8]. IL 12 is considered a crucial cytokine to induce IFN $\gamma$ production but in the absence of IL 12 other cytokines, such as IL 18, could contribute to resistance to $L$. major. IL 18 seems to be able to inhibit the Th2 default response [21]. However, in the absence of IL 12, IL 18 is not sufficient to drive immunity to L. major and IL 18 is not required in IL 12 competent mice [21]. These data indicate that alternative factors can co operate with IL 12 in redirecting the early Th2 response and can affect the early stages of $L$. major infection in resistant mice but IL 12-IL 12R signaling is essential in establishing and maintaining a protective Th1 response. Healed C57BL/6 mice when treated with anti IL 12 antibodies reactivate their infection [22]. Additionally, primed Th1 cells from healed mice cannot transfer immunity to IL 12 deficient mice [23]; IL 12 seems to be required to prevent the differentiation of newly emerging precur sors of Th2. As for the cell source of cytokines, $\mathrm{CD}^{+} \mathrm{T}$ cells seem to be implicated in IL 10 production [8].

Mouse DCs, including epidermal Langerhans cells (LCs) take up $L$. major parasites, acquire a mature phenotype and release IL $12 \mathrm{p} 40$ in vitro [24]. Their role in producing IL 12 in vivo has also been shown $[15,25,26]$. The ability of LCs to transport the parasites from infected skin to the draining lymph nodes seems to rely on the expression of CCR2. Mice of a resistant background, deficient in CCR2 exhibit deficient LC migration and are highly susceptible to $L$. major infection [27].

Natural killer (NK) cells have been related to Th1 develop ment through IFN $\gamma$ production. However, they are not essen tial for resistance. Immune deficient $\mathrm{T}$ cell reconstituted mice, which selectively lack NK cells, have efficient IL 12 dependent IFN $\gamma$ production by $\mathrm{CD}^{+} \mathrm{T}$ cells and heal their lesions. [27,28].

The crucial role of $\mathrm{CD}^{+} \mathrm{T}$ cells to mediate protection against $L$. major infection is firmly established $[8,25]$. The protective role of $\mathrm{CD}^{+} \mathrm{T}$ cells is more controversial [8].
Two key features of natural transmission (low parasite and intradermal inoculation) are important in order to obtain in the murine model, similar conditions to the disease in man. Using this approach, it has been shown that both $\mathrm{CD}^{+}$and CD8 $\mathrm{T}$ cells are required for the control of primary L. major infection [29]. Recently, the outcome of infection in anti CD8 treated and CD8 deficient mice showed that these cells are required for the control of primary infection in the skin. These results are consistent with clinical studies reporting high numbers of antigen specific $\mathrm{CD} 8^{+} \mathrm{T}$ cells in lesions and peripheral blood during acute stage of the lesions and during the healing process [30]. The existence of a latent infection in resistant mice after clinical cure has been demonstrated. Moreover, these healed mice are able to maintain life long immunity to reinfection. IL 10 has a crucial role in chronic ity, demonstrated by the inability of the parasite to establish a persistent infection after healing in IL 10 deficient mice and by the sterile immunity that was achieved in wild type mice treated during the chronic phase with antiIL 10R antibody. The source of IL 10 in C57BL/6 was found to be a popula tion of $\mathrm{CD} 44^{+} \mathrm{CD} 25^{+} \mathrm{CD} 45 \mathrm{RB}^{\text {low }} \mathrm{T}$ cell subset immunoregu latory $\mathrm{T}$ cells [31]. Importantly, the IL 10 deficient and IL $10 \mathrm{R}$ antibody treated mice that achieved sterile cure were no longer immune to reinfection [31], which indicated that the maintenance of effector $\mathrm{T}$ cells requires antigen persistence.

\section{Visceral leishmaniasis}

VL lacks a good animal model, making it difficult to deter mine the protective mechanisms against $L$. donovani. The golden hamster has been used for a long time, since it mim ics several aspects of human disease (anemia, hyperglob ulinemia and cachexia). However, the difficulty in exploring immunological responses in hamsters leads to a preferential use of the mouse models. Studies in mice have explored the immune mechanisms important for the development of organ specific immunity, which results into clearance of par asites from the liver but not from the spleen [32,33]. Recent studies indicate the importance of cytotoxic $\mathrm{T}$ lymphocyte associated antigen (CTLA) 4 engagement in T cells and of TGF $\beta$ production in the immunopathogenesis of murine VL. Activation of $\mathrm{CD}^{+} \mathrm{T}$ cells from $L$. donovani infected mice by antigen or anti CD3 leads to an intense CTLA4 mediated TGF $\beta_{1}$ production, which increases parasite rep lication and reciprocally regulates IFN $\gamma$ production [34]. Blockade of CTLA 4 enhances host resistance, increasing the expression of inducible protein (IP) 10, a chemokine directly related to the frequency of IFN $\gamma$ producing cells [35]. The course of infection with $L$. donovani was examined in mice lacking the gene for IL $10 . \mathrm{BALB} / \mathrm{c} \mathrm{IL} 10^{\prime}$, as well as $\mathrm{C} 57 \mathrm{BL} / 6 \mathrm{IL} 10^{\prime}$ mice, were highly resistant to $L$. donovani infection, as evidenced by liver parasite burdens which were tenfold lower than those in control mice after 14 days of infection. Enhanced resistance was accompanied by increased production of IFN $\gamma$ and nitric oxide in BALB/c IL $10^{\prime}$ mice [36]. 
DCs from mice with chronic $L$. donovani infection fail to migrate from the marginal zone to the periarteriolar region of the spleen. Defective localization was attributable to TNF $\alpha$ dependent IL 10 mediated inhibition of CCR7 expression. Effective immunotherapy was achieved with CCR7 expressing DCs, without the need of identifying protective Leishmania antigens [37].

\section{Immunological aspects of human leishmaniasis}

CL patients exhibit anti Leishmania cell mediated immunity (CMI). ML is considered to be the hyper responsive pole since these patients exhibit a potent anti Leishmania CMI. With disease progression, ML patients tend to develop larger intradermal skin test reactions and their lymphocytes exhibit higher proliferative responses and production of IFN $\gamma$ than cells from CL patients. On the other hand, DCL patients have transient weak responses or do not exhibit any anti Leishmania CMI. Delayed type hypersensitivity (DTH) is negative and their lymphocytes do not respond to leishmanial antigen either by proliferation or cytokine production. DCL patients present an antigen specific immunosuppression, mounting normal responses to other antigens.

The clinical spectrum of leishmaniasis and control of the infection are influenced by the parasite-host relationship. Th1 crossed Th2 dichotomy is probably influenced by cytokine patterns present during the very early stages of Leishmania survival inside the macrophage. In humans, pro duction of IFN $\gamma$ is associated with the control of infection in children infected by Leishmania infantum. In VL, impair ment of IFN $\gamma$ production and high IL 4 and IL 10 levels (Th2 cytokines) are observed in antigen stimulated periph eral blood mononuclear cells (PBMCs). Moreover, IL 12 restores IFN $\gamma$ production and enhances the cytotoxic response. In human leishmaniasis, IL 10 is the cytokine involved in downregulation of IFN $\gamma$ production, since anti IL $10 \mathrm{mAb}$ restores in vitro IFN $\gamma$ production and lympho proliferative responses and IL 10 abrogates the effect of IL 12 (reviewed in [38]). Cure of VL is associated with the resto ration of IFN $\gamma$ production. IL 12 plays an important role in the ability of treated VL patients to produce IFN $\gamma$, suggest ing the importance of this cytokine in maintaining a Th1 response in man. Interestingly, IL 10 but not IL 4 or TGF $\beta$, is able to inhibit human Th1 responses [39] In CL and MCL, high levels of IFN $\gamma$ are found in L. amazonensis stimulated PBMC. However, low or absent IFN $\gamma$ levels were observed in antigen stimulated PBMCs from $50 \%$ of subjects with less than 60 days of disease. This response was restored by IL 12 or anti IL $10 \mathrm{mAbs}$ [40]. Later during disease, high levels of IFN $\gamma$ and TNF $\alpha$ are found both in CL and MCL, with decreased TNF $\alpha$ levels after treatment. IFN $\gamma$ and TNF $\alpha$ seem to be involved both in the control of parasite multipli cation in the early phases of Leishmania infection and in tissue damage seen in tegumentary leishmaniasis [40].

The role of cytotoxicity in the defense mechanisms or tissue damage of human CL is not yet well known. Machado and coworkers [41]. observed the presence of $\mathrm{NK}, \mathrm{CD} 8^{+}$and $\mathrm{CD}^{2} 5 \mathrm{RO}^{+} \mathrm{T}$ cells, as well as the strong expression of a mole cule associated with cytotoxic properties (TIA 1) in the der mal cell infiltrate of lesions from CL patients. The presence of these cells with cytolytic capacity in CL argues in favor of an active participation of $\mathrm{NK}$ and $\mathrm{CD}^{+} \mathrm{T}$ cells in the pathogen esis of disease. These cells may play a role in the parasite kill ing but also in ulcer development [41].

\section{Vaccines}

\section{Human studies with first generation vaccines}

Active immunization against leishmaniasis has been attempted for many years. The original version of a human vaccine consisted of inoculating material from lesions into naive individuals using a thorn since producing a mild disease precluded from developing a severe disfigurement after subsequent natural exposure.

The first generation of vaccines against leishmaniasis consisted of autoclaved Leishmania promastigotes with or without bacil lus of Calmette and Guerin (BCG) as adjuvant. This vaccine has been tested in Phase II field efficacy trials against CL and VL. In a randomized, BCG controlled, double blind trial in Sudan, against VL, no evidence was found that the two injections of the vaccine (autoclaved L. major $[\mathrm{ALM}]$ ) resulted in significant pro tection against VL when compared with BCG alone [42]. How ever, the vaccine induced higher rates of leishmanin skin test (LST) conversion relative to BCG alone. Individuals who con verted LST had a significantly lower incidence of disease com pared to LST nonresponders. Similarly, in Iran, the single injec tions and triple injections of ALM BCG reduced the incidence of CL in LST converted individuals but not significant overall protection compared with BCG alone [43].

Vaccination trials in Brazil and Ecuador have demonstrated that a cocktail of five killed Leishmania stocks or a single strain of L. amazonensis induces significant protection from natural infection [44 46].

These studies indicated that DTH conversion could be used as a surrogate marker for protective immunity.In a monkey model of cutaneous leishmaniasis, protective immunity was achieved using killed $L$. amazonensis coadministered with recombinant IL 12 as adjuvant [47].

The human protective responses against Leishmania in humans are not entirely understood impairing rational approaches to vac cine development. Animal models currently available are perhaps somewhat, but not entirely, predictive of how effective a vaccine candidate will perform in man. It is also impossible to test several candidate antigens in vaccine trials due to economic constraints. In this sense, we have tested an $c$ system to evaluate the response of naive individuals.

\section{In vitro priming assay}

It has been shown that an in vitro system using lymphoid cells from naive mice primed with $L$. major promastigotes mimics in vivo responses in murine leishmaniasis [48]. This system has also been used with human cells in order to explore early events of anti Leishmania responses. 
Most individuals developed Th1 or Th0 anti Leishmania $\mathrm{T}$ cell lines and infected macrophages from Thl responders produced IL 12. Th0 responders who produced little or no endogenous IL 12 could be converted to the Thl phenotype by addition of IL 12 during priming [49].

Using IVP, our group evaluated a large number of normal volunteers both before and after receiving a Leishmania vaccine. In this way we could evaluate if in vitro primary responses were able to predict in vivo antileishmanial responses in man. PBMCs from volunteers who had negative responses against Leishmania, both cell mediated and antibodies, were used for in vitro stimulation with Leishmania antigen, IFN $\gamma$ levels were then monitored. Volunteers fell into two different types of responders: those who produced low amounts of IFN $\gamma$ (low responders) and those who produced high levels of this cytokine (high responders). Low responder volunteers remained low producers of IFN $\gamma 40$ days after vaccination, whereas high responders exhibited increased IFN $\gamma$ production after vaccination. However, 6 months postvaccination, all indi viduals tested were producing similarly high levels of IFN $\gamma$ upon stimulation of their PBMCs with Leishmania promastig otes, indicating that the low producers in vitro are slow in vivo responders to vaccination. High IFN $\gamma$ producers exhibited an increased frequency of activated $\mathrm{CD} 8^{+} \mathrm{T}$ lymphocytes both in vitro and in vivo, as compared with low/slow IFN $\gamma$ produc ers [50]. Such findings suggest that the IVP response is able to predict the rate of postvaccination response and can contribute to a leishmanial antigen screening to test future potential candi dates for vaccines. Although all vaccinated individuals eventu ally present a potent anti Leishmania CMI response, a delay in the rate of mounting the CMI response may influence resistance against leishmaniasis.

\section{Live attenuated vaccines}

In the same IVP system, we compared immune responses gen erated by PBMCs from normal volunteers stimulated with wild $L$. major or with a genetically manipulated parasite derived from L. major, L. major dhfr-ts. This mutant lacks a gene essen tial for long term survival in the mammalian host which codes for the enzyme dihydrofolate reductase-thymidylate synthetase (DHFR-TS). It has been shown that these organisms can invade and undergo a limited number of replications in macro phages without producing disease. In a mouse model, parasites lacking DHFR-TS induced protection against infection with L. amazonensis [51]. In our IVP system, we observed that cells from normal volunteers developed a preferential Th1 response and no significant differences were observed between $d h f r-t s^{-}$ and $L$. major concerning IFN $\gamma$ production by in vitro stimu lated PBMCs from normal volunteers [52]. An attenuated line of $L$. mexicana was also used successfully to protect against homologous infection. This mutant lacked two genes coding for the cysteine proteases $c p a$ and $c p b$ [53].

The use of attenuated organisms is very attractive because their use resembles the natural course of infection and may lead to similar immune responses. Attenuated organisms cause a limited infection, resulting in lower antigen load favoring a stronger Thl response [54]. The disadvantages of such vaccines are the logistics of their large scale production and distribution in the field.

\section{Vaccine approaches using defined antigens}

Some of the target antigens are species and life cycle stage spe cific, while others are shared by promastigotes and amastigotes. The immune responses in leishmaniasis can range from protec tive to harmful. These differences in the quality of the response are at least partly due to predominance of Th1 or Th2 cytokines and may be greatly influenced by antigen dose [55]. This is a major concern in vaccine approaches with defined antigens.

Recombinant antigens can be delivered as purified proteins, as naked DNA or as bacteria manufacturing the proteins in situ. Manipulations now allow targeting the antigen to specific locations or to particular APCs, such as DCs or LCs, which are considered essential for the initiation of primary $\mathrm{T}$ cell responses. Injection of bacteria or naked DNA may have the added advantage of providing an adjuvant effect, which may activate these APCs.

Synthetic peptides have been in use for over 10 years. How ever, several considerations make the peptide antigens less attractive as potential candidate vaccines, such as the magni tude of $\mathrm{T}$ cell memory induced, the inability of all individuals in the population to respond to the peptide and the logistics of production. Since the antigenic peptide is processed and pre sented to T cells in the context of MHC class I or class II and since not all peptides associate with all MHC types, some pep tides will not be recognized by all individuals in the population. There are additional problems in the ability to respond to indi vidual peptides due to failure of processing, cleavage, transport or deletion of determined $\mathrm{T}$ cell specificities. Another reason for the low success rate of subunit vaccines is that some polypeptides may be a minor immunogens and so even though they may be excellent in a cocktail vaccine, individually they may provide only partial protection. Despite these problems, several Leishmania gp63 peptides have been tested successfully in animal models [56].

In general, the success of subunit vaccines based on recom binant proteins or peptides has been variable or poor. Mice immunized with killed promastigotes or recombinant proteins plus IL 12 as an adjuvant had a high level of protection when challenged 2-4 weeks after vaccination but they had already lost substantial protection when challenged after 12 weeks [57-59]. Immunity could be maintained by repeated administra tion of antigen or IL 12 [22] or by antigen and/or IL 12 deliv ered by plasmid DNA [57-59]. As mentioned before, there may be a need of persisting parasites in the host organism to main tain immunity [31]. Therefore, it may not be possible for subunit vaccine to induce long lasting immunity on its own.

One approach generating great interest is that of inducing protective immune responses by injecting engineered DNA sequences from infectious organisms against which protec tion is desired. The ability of plasmid DNA encoding 
specific antigens to induce both $\mathrm{CD}^{+}$and $\mathrm{CD} 8^{+} \mathrm{T}$ cell responses could be of particular use for protection against diseases that require CMI, including leishmaniasis. The low production costs and high structural ability of DNA make DNA vaccination a very attractive tool for immunization. For instance, it has been shown that immunization with rVV (vaccinia virus) expressing the L. amazonensis gp46 antigen elicits significant protection and long term immunological memory in BALB/c mice [60]. Experiments in mice and other animal models have shown that a combination of priming with DNA and boosting with recombinant vaccinia virus expressing the same protein is associated with high immuno genicity and protective efficacy against several infectious dis eases. Using this approach, good protection against $L$. major in mice [55] and against $L$. infantum in dogs [61] has been obtained using this heterologous prime-boost immunization regime. Many different DNA vaccines, coding for different leishmanial antigens, have been tested in mouse models, showing good results $[57,62,63]$ and therefore, this kind of approach should become a promise for leishmaniasis vac cines. More recently, it has been shown that the combination of antigens (cocktail) in DNA vaccines might be a more effective approach, providing stronger protection [64].

A recent and interesting approach is the development of minimalistic immunogenically defined gene expression (MIDGE) vectors [65]. The linear vectors contain only the minimum sequences required for gene expression and can be chemically modified to increase the immune responses. The authors demonstrated that MIDGE vectors coding for LACK antigen confer a highly effective protection against Leishmania infection in susceptible BALB/c mice. Protection could be achieved at lower doses of this vector when compared with conventional plasmids.

\section{Adjuvants}

Another issue concerning peptide vaccines is related to the use of different adjuvants. In most experimental systems, adju vants are essential to generate protective immunity. However, the most effective adjuvants generally cause strong inflamma tion, which may preclude their use in humans because of unacceptable side effects. Vaccination with either soluble leishmanial antigen or recombinant leishmanial protein plus IL 12 protein did not confer long term protection [59]. How ever, if leishmanial protein plus IL 12 protein vaccinated mice were boosted with IL 12 protein, control of infection was better sustained [22]. Furthermore, mice vaccinated with leishmanial antigen plus IL 12 DNA also showed long term Th1 immunity and protection [58].

Recently, some reports have shown the possibility of use $\mathrm{CpG}$ oligodeoxynucleotides (ODN) as potent adjuvants in different vaccine systems including diseases requiring Th1 immune responses. ODNs have been shown to stimulate macrophages and DC sto synthesize several cytokines, including IL 12, IL 18, TNF $\alpha$, IFN $\alpha, \beta$ and $\gamma$ and to upregulate costimulatory molecules, such as CD40 and
MHC class II; [66,67]. The range and level of cytokine pro duction vary according to each ODN sequence and its par ticular modifications [68]. Moreover, $\mathrm{CpG}$ ODN have been shown to activate DCs, leading to the presentation of solu ble protein to class I restricted $\mathrm{T}$ cells and the induction of CTL responses [67,69]. In studying the role of CpG ODN as a prophylactic vaccine adjuvant, leishmanial protein plus CpG ODN was reported to confer some protection against a challenge with $L$. major [70]. More recently, it has been observed that the ability of CpG ODN to confer long term immunity and protection (up to 12 weeks after vaccination) when used as a vaccine adjuvant with autoclaved $L$. major or a recombinant leishmanial protein. These studies were per formed in susceptible and resistant mouse strains and the results showed that in $\mathrm{C} 57 \mathrm{BL} / 6$ mice this protection was observed after 6 months of vaccination. These vaccines induced L. major Th1 and $\mathrm{CD} 8^{+}$responses [71]. However, it is still unclear whether $\mathrm{CpG}$ ODN will be a feasible approach in humans, since no IL 12 inducing $\mathrm{CpG}$ sequences have been identified.

\section{Vector directed vaccine approaches}

The sand fly injects the mammalian host with Leishmania in the presence of its saliva. The saliva of blood sucking animals contains a varied repertoire of molecules that modulates their hosts' hemostatic, inflammatory and immune responses. In mice, these products seem to exacerbate the infection with Leishmania and may, in fact be mandatory for the establish ment of the parasite in the vertebrate host. It has been shown that components of Lutzomyia longipalpis or Phlebotomus papatasi salivary gland lysates mixed with $L$. major resulted in substantially larger lesions compared with controls [72,73]. Recent studies using the murine ear model of infection have shown it is possible to transmit $L$. major by the bite of its nat ural vector, $P$. papatasi, to $\mathrm{BALB} / \mathrm{c}$ and $\mathrm{C} 57 \mathrm{Bl} / 6$ mice. Inter estingly, for both $\mathrm{BALB} / \mathrm{c}$ and $\mathrm{C} 57 \mathrm{Bl} / 6$ mice, prior exposure to $P$. papatasi bites resulted in a striking reduction in the severity of the dermal lesions and the pre exposed mice had over 1000 fold reduction in the mean number of amastigotes per infected ears, transforming them in a bad source of trans mission to uninfected sand flies [74]. Whereas enhancement of Leishmania transmission by saliva is probably due to immu nomodulatory components of sand fly saliva, an explanation of the anti Leishmania effect resulting from host immuniza tion against salivary antigen is not straightforward. Immunity in this system could derive from neutralization of salivary immunomodulators, such as the peptide maxadilan from $L$. longipalpis [73]. Alternatively, immunity could derive from a DTH reaction at the site of the bite generated by a cellular response to salivary antigens injected by the fly $[74,75]$. This particular reaction could turn the lesion and is surroundings into an inhospitable site for the establishment of Leishmania infection in the new host, or it could modify the environ ment priming the initial events of the host immune reaction to Leishmania. A $15 \mathrm{kDA}$ component from P. papatasi saliva, 
when extracted from sodium dodecyl sulfate (SDS) polyacry lamide gels, was able to protect mice challenged with para sites plus salivary gland homogenate (SGH) [76]. A DNA vac cine containing the cDNA for the $15 \mathrm{kDa}$ protein provided the same protection, even in B cell knockout mice. The results indicate that a DTH response against saliva provides most or all the protective effects of this vaccine and that sali vary glands or their cDNAs are viable vaccine targets against leishmaniasis [76].

We have shown that serum samples from children living in an endemic area for visceral leishmaniasis have anti SGS immunoglobulin ( $\mathrm{Ig}) \mathrm{G}$ antibodies that differentially recog nize salivary gland antigens. Individuals with a positive anti Leishmania DTH response exhibited anti Lu. longipalpis saliva antibodies. A positive correlation was observed between anti $\mathrm{Lu}$. longipalpis antibodies and anti Leishmania DTH response but no correlation was observed between anti saliva and anti Leishmania serologic status [77]. More recently, we observed that children who experience anti Leishmania DTH conversion have an increase in antisand fly saliva antibodies, showing that the development of antipara site DTH coincides temporally with the development of anti $\mathrm{Lu}$. longipalpis saliva antibodies [78]. It is tempting to speculate that neutralization of sand fly salivary components by antibodies or cellular response to salivary proteins allows a more efficient mounting of an anti Leishmania CMI response, probably due to the development of a Th1 response against the parasite. The higher antibodies levels observed in individuals who converted their anti Leishmania DTH sug gest that mounting antisaliva antibody response is linked to developing CMI against Leishmania. We also observed that sera from these children recognized more frequently at least two salivary proteins, 45 and $35 \mathrm{kDa}$, which may, respec tively, be similar to the Yellow related protein and to the sali vary apyrase from the saliva of Lu. longipalpis [79]. Therefore, these proteins could be candidates to either study the expo sure to sand flies bites or as vaccine candidates to control infection with $L$. chagasi.

An effective leishmaniasis vaccine will be one that prevents the development of disease. The distinction between vaccines designed to prevent disease is an important one. A decrease in infection, such as was achieved through the prior exposure to sand fly bites or injection of purified protein, will not neces sarily confer immunity to the parasite itself or prevent subse quent disease progression. Leishmania has a tissue stage that is responsible for the pathology and is distinct from the promas tigotes transmitted by the sand fly. Thus, vaccines that only prevent infection and do not establish immunity to tissue par asites may be a risk. On the other hand, it is possible to immunize against sand fly components and produce a low grade infection, with a degree of immunity to the amastigote sufficient to prevent disease [80]. Probably, limiting the number of surviving parasites after exposure via a DTH reac tion caused by sand fly bites, is the reason that there are so many asymptomatic human infections in certain foci.
Ideally, through a combination of vaccine components directed against both vector and pathogen targets, safe and long lasting immunity can be achieved.

\section{Expert opinion \& five year view}

Development of an anti Leishmania vaccine has proven to be a difficult endeavor. Use of several antigens, selected through diverse approaches, did not achieve an acceptable level of protection. It is possible that insufficient knowledge of Leishmania pathogenesis represents the main root of repeated insuccesses. There are numerous recent examples of problems revisited that have led to changes in our under standing of leishmaniasis. The use of subcutaneous route of infection, the fundamental role of sand fly saliva in the early steps of leishmanial infection, a regulatory role of $\mathrm{CD} 8^{+}$ $\mathrm{T}$ cells and the influence of DCs are some of these aspects. Another limiting issue in the development of a vaccine against leishmaniasis is the need for a protective cell medi ated immune response. A renewed effort in evaluating new adjuvants, some of them tailored for providing elements known to be important in building a protective Th1 immune response, offers hope.

After the hurdle of demonstrating effective antigens in experimental models, we will be faced with the challenge of testing them in man. Due to epidemiological considerations, a fluctuating incidence in most endemic areas among other aspects, vaccine assays may not be feasible for a large number of candidate antigens. Improving ways of selecting appropriate candidates for human protection in this disease may alleviate this problem pinpointing the best products for clinical assays. Another neglected area of considerable importance is the evaluation of reliable surrogate markers of protection. Development in this field directed to other infections, which are also dependent on CMI protection, may be of use in leishmaniasis.

A concerted effort in all these fields would be desirable and could offer some, albeit cautious, optimism.

\section{Acknowledgements}

Our studies were funded by the Brazilian National Research Council (CNPq), the TMRC NIH and Immunology Investigation Institute. 


\section{Key issues}

Different clinical manifestations of leishmaniasis, caused by different species of Leishmania, complicate the development of a vaccine.

Infection by Leishmania results in a complex immune response in the vertebrate host, which hampers the design of an effective vaccine against the parasite.

The use of new technologies and experimental systems have allowed a better understanding of the mechanisms underlying the protective immune response against Leishmania.

First generation vaccines made use of inactivated parasites and many clinical trials have showed that a partial protection against the infection has been obtained.

Genetic manipulation of the parasite has been used in experimental models or in vitro priming (IVP) assays showing successful results due to, mainly, a lower antigen load and a stronger $T$ helper response.

DNA vaccination using specific parasite antigens has proven to be the most promising approach, since high levels of protection were observed in different experimental models.

The use of sand fly saliva components in vaccine design is the newest vaccination approach. The studies in experimental models as well as of individuals in an endemic area for visceral leishmaniasis have showed the potential ability of these salivary gland products to protect against the disease rather than to protect against the parasite.

\section{References}

Papers of special note have been highlighted as:

- of interest

•• of considerable interest

1 Bittencourt A, Barral Netto M. Leishmaniasis. In: Tropical Pathology, Vol. 8, 2nd Edition. Doerr W, Seifert G(Eds). Springer, Berlin, Germany, 597-651 (1995).

2 Gontijo B, de Carvalho Mde L. [American cutaneous leishmaniasis]. Rev. Soc. Bras. Med. Trop. 36, 71-80 (2003).

3 Harris E, Kropp G, Belli A, Rodriguez B, Agabian N. Single step multiplex PCR assay for characterization of New World Leishmania complexes. J. Clin. Microbiol. 36, 1989-1995 (1998).

4 Castilho TM, Shaw JJ, Floeter Winter LM. New PCR assay using glucose 6 phosphate dehydrogenase for identification of Leishmania species. $J$. Clin. Microbiol. 41, 540-546 (2003).

5 Murray HW, Montelibano C, Peterson R, Sypek JP. Interleukin 12 regulates the response to chemotherapy in experimental visceral leishmaniasis. J. Infect. Dis. 182, 1497-1502 (2000).

6 Murray HW. Treatment of visceral leishmaniasis (kala azar): a decade of progress and future approaches. Int. J. Infect. Dis. 4, 158-177 (2000).

Review of the evolution of treatment of visceral leishmaniasis, in terms of the interaction of the immune response and chemotherapy, highlighting therapeutic successes and failures, in terms of advantages and disadvantages of current treatments, and looking at future therapeutic approaches to the management of this disseminated intracellular protozoal infection. IL 12 regulates host IFN $\boldsymbol{\gamma}$ dependent and independent responses that permits and/or enhances leishmanicidal activity.

7 Bafica A, Oliveira F, Freitas LA, Nascimento EG, Barral A. American cutaneous leishmaniasis unresponsive to antimonial drugs: successful treatment using combination of $N$ methylglucamine antimoniate plus pentoxifylline. Int. J. Dermatol. 42, 203-207 (2003).

8 Sacks D, Noben Trauth N. The immunology of susceptibility and resistance to Leishmania major in mice. Nat. Rev. Immunol. 2, 845-858 (2002). Thorough discussion of the new findings leading to susceptibility and resistance to infection by L. major in mice.

9 Groux H, Cottrez F, Rouleau M et al. A transgenic model to analyze the immunoregulatory role of IL 10 secreted by antigen presenting cells. J. Immunol. 162, 1723-1729 (1999).

10 Bogdan C, Rollinghoff M, Diefenbach A. Reactive oxygen and reactive nitrogen intermediates in innate and specific immunity. Curr. Opin. Immunol. 12, 64-76 (2000).

Review of the many different functions of $\mathrm{NO}$ and its role on immunoregulation of protozoa infections.

11 Mattner F, Magram J, Ferrante J et al.
Genetically resistant mice lacking interleukin 12 are susceptible to infection with Leishmania major and mount a polarized Th2 cell response. Eur: J. Immunol. 26, 1553-1559 (1996).

12 Nishikomori R, Gurunathan S, Nishikomori K, Strober W. BALB/c mice bearing a transgenic IL 12 receptor $\beta 2$ gene exhibit a nonhealing phenotype to Leishmania major infection despite intact IL 12 signaling. J. Immunol. 166, 6776-6783 (2001).

13 Tacchini Cottier F, Zweifel C, Belkaid Y et al. An immunomodulatory function for neutrophils during the induction of a $\mathrm{CD}^{+}{ }^{+} \mathrm{Th} 2$ response in $\mathrm{BALB} / \mathrm{c}$ mice infected with Leishmania major. $J$. Immunol. 165, 2628-2636 (2000).

14 Gu L, Tseng S, Horner RM, Tam C, Loda $\mathrm{M}$, Rollins BJ. Control of TH2 polarization by the chemokine monocyte chemoattractant protein 1. Nature 404, 407-411 (2000).

15 von Stebut E, Belkaid Y, Jakob T, Sacks DL, Udey MC. Uptake of Leishmania major amastigotes results in activation and interleukin 12 release from murine skin derived dendritic cells: implications for the initiation of anti Leishmania immunity. $J$. Exp. Med. 188, 1547-1552 (1998).

16 Von Stebut E, Ehrchen JM, Belkaid Y et al. Interleukin $1 \alpha$ promotes Thl differentiation and inhibits disease progression in Leishmania majorsusceptible BALB/c mice. J. Exp. Med. 198, 191-199 (2003). 
17 Iwasaki A. The importance of CDl $1 b^{+}$ dendritic cells in $\mathrm{CD}^{+} \mathrm{T}$ cell activation in vivo: with help from interleukin 1. J. Exp. Med. 198, 185-190 (2003).

18 Filippi C, Hugues S, Cazareth J, Julia V, Glaichenhaus N, Ugolini S. CD4 ${ }^{+} \mathrm{T}$ cell polarization in mice is modulated by strain specific major histocompatibility complex independent differences within dendritic cells. J. Exp. Med. 198, 201-209 (2003).

19 Matthews DJ, Emson CL, McKenzie GJ, Jolin HE, Blackwell JM, McKenzie AN. IL 13 is a susceptibility factor for Leishmania major infection. J. Immunol. 164, 1458-1462 (2000).

20 Li J, Hunter CA, Farrell JP. Anti TGF $\beta$ treatment promotes rapid healing of Leishmania major infection in mice by enhancing in vivo nitric oxide production. J. Immunol. 162, 974-979 (1999).

21 Monteforte GM, Takeda K, Rodriguez Sosa M, Akira S, David JR, Satoskar AR. Genetically resistant mice lacking IL 18 gene develop Th1 response and control cutaneous Leishmania major infection. $J$. Immunol. 164, 5890-5893 (2000).

22 Stobie L, Gurunathan S, Prussin C et al. The role of antigen and IL 12 in sustaining Th1 memory cells in vivo: IL 12 is required to maintain memory/effector Thl cells sufficient to mediate protection to an infectious parasite challenge. Proc. Nat. Acad. Sci. USA 97, 8427-8432 (2000).

23 Park AY, Hondowicz BD, Scott P. IL 12 is required to maintain a $T h 1$ response during Leishmania major infection. J. Immunol. 165, 896-902 (2000).

24 von Stebut E, Belkaid Y, Nguyen BV, Cushing M, Sacks DL, Udey MC, Leishmania major infected murine langerhans cell like dendritic cells from susceptible mice release IL 12 after infection and vaccinate against experimental cutaneous Leishmaniasis. Eur: J. Immunol. 30, 3498-3506 (2000).

25 Mohrs M, Ledermann B, Kohler G, Dorfmuller A, Gessner A, Brombacher F. Differences between IL 4 and IL 4 receptor $\alpha$ deficient mice in chronic leishmaniasis reveal a protective role for $\mathrm{IL}$ 13 receptor signaling. J. Immunol. 162 , 7302-7308 (1999).

26 Malherbe L, Filippi C, Julia V et al. Selective activation and expansion of high affinity $\mathrm{CD}^{+} \mathrm{T}$ cells in resistant mice upon infection with Leishmania major. Immunity $13,771-782(2000)$.

27 Sato N, Ahuja SK, Quinones M et al. CC chemokine receptor (CCR)2 is required for langerhans cell migration and localization of T helper cell type 1 (Thl) inducing dendritic cells. Absence of CCR2 shifts the Leishmania major resistant phenotype to a susceptible state dominated by Th2 cytokines, B cell outgrowth, and sustained neutrophilic inflammation. J. Exp. Med. 192, 205-218 (2000).

28 Satoskar AR, Stamm LM, Zhang X et al. Mice lacking NK cells develop an efficient Th1 response and control cutaneous Leishmania major infection. J. Immunol. 162, 6747-6754 (1999).

29 Belkaid Y, Von Stebut E, Mendez S et al. $\mathrm{CD}^{+} \mathrm{T}$ cells are required for primary immunity in C57BL 6 mice following low dose, intradermal challenge with Leishmania major. J. Immunol. 168, 3992-4000 (2002).

The authors show the role of $\mathrm{CD}^{+} \mathrm{T}$ cells in the protective response against Leishmania.

30 Gaafar A, Veress B, Permin H, Kharazmi A, Theander TG, el Hassan AM. Characterization of the local and systemic immune responses in patients with cutaneous leishmaniasis due to Leishmania major. Clin. Immunol. 91, 314-320 (1999).

31 Belkaid Y, Piccirillo CA, Mendez S, Shevach EM, Sacks DL. CD4 CD25 regulatory $\mathrm{T}$ cells control Leishmania major persistence and immunity. Nature 420 , 502-507 (2002).

This paper clearly demonstrates the presence of T reg in the lesion caused by $L$. major and the importance of IL 10 to maintain the parasitism and the immunity against the parasite.

32 Engwerda CR, Kaye PM. Organ specific immune responses associated with infectious disease. Immunol. Today 21, $73-78(2000)$.

33 Kaye PM, Gorak P, Murphy M, Ross S. Strategies for immune intervention in visceral leishmaniasis. Ann. Trop. Med. Parasitol. 89, (Suppl. 1), 75-81 (1995).

34 Gomes NA, Gattass CR, Barreto De Souza $\mathrm{V}$, Wilson ME, DosReis GA. TGF $\beta$ mediates CTLA 4 suppression of cellular immunity in murine kalaazar. J. Immunol. 164, 2001-2008 (2000).

The authors show the importance of CTLA 4 engagement and TGF $\boldsymbol{\beta}$ production in causing immunosupression in VL.

35 Murphy ML, Cotterell SE, Gorak PM, Engwerda CR, Kaye PM. Blockade of CTLA 4 enhances host resistance to the intracellular pathogen, Leishmania donovani. J. Immunol. 161, 4153-4160 (1998).

36 Murphy ML, Wille U, Villegas EN, Hunter
CA, Farrell JP. IL 10 mediates susceptibility to Leishmania donovani infection. Eur. $J$. Immunol. 31, 2848-2856 (2001).

37 Ato M, Stager S, Engwerda CR, Kaye PM Defective CCR7 expression on dendritic cells contributes to the development of visceral leishmaniasis. Nat. Immunol. 3, 1185-1191 (2002).

The authors show the importance of CCR7 in the migration of DC in the spleen of mice infected with $L$. donovani and that defective DC migration plays a major role in the pathogenesis of this disease. It is also shown that immunosuppression is mediated, at least in part, through the spatial segregation of DCs and T cells.

38 Barral Netto M, Brodskyn C, Carvalho EM, Barral A. Human

leishmaniasis/cytokines.bahia.br. Braz. J. Med. Biol. Res. 31, 149-155 (1998).

39 Bacellar O, D'Oliveira A, Jr., Jeronimo S, Carvalho EM. IL 10 and IL 12 are the main regulatory cytokines in visceral leishmaniasis. Cytokine 12, 1228-1231 (2000).

40 Ribeiro de Jesus A, Almeida RP, Lessa H, Bacellar O, Carvalho EM. Cytokine profile and pathology in human leishmaniasis. Braz. J. Med. Biol. Res. 31, 143-148 (1998).

41 Machado P, Kanitakis J, Almeida R, Chalon A, Araujo C, Carvalho EM. Evidence of in situ cytotoxicity in American cutaneous leishmaniasis. Eur. J. Dermatol. 12, 449-451 (2002).

42 Khalil EA, El Hassan AM, Zijlstra EE et al. Autoclaved Leishmania major vaccine for prevention of visceral leishmaniasis: a randomised, double blind, $\mathrm{BCG}$ controlled trial in Sudan. Lancet 356, 1565-1569 (2000).

43 Sharifi I, FeKri AR, Aflatonian MR et al. Randomised vaccine trial of single dose of killed Leishmania major plus BCG against anthroponotic cutaneous leishmaniasis in Bam, Iran. Lancet 351, 1540-1543 (1998).

44 De Luca PM, Mayrink W, Alves CR et al. Evaluation of the stability and immunogenicity of autoclaved and nonautoclaved preparations of a vaccine against American tegumentary leishmaniasis. Vaccine 17, 1179-1185 (1999).

45 Armijos RX, Weigel MM, Aviles $\mathrm{H}$, Maldonado R, Racines J. Field trial of a vaccine against New World cutaneous leishmaniasis in an at risk child population: safety, immunogenicity, and efficacy during the first 12 months of follow up. J. Infect. 
Dis. 177, 1352-1357 (1998).

46 Marzochi KB, Marzochi MA, Silva AF et al. Phase 1 study of an inactivated vaccine against American tegumentary leishmaniasis in normal volunteers in Brazil. Mem. Inst. Oswaldo Cruz 93, 205-212 (1998).

47 Kenney RT, Sacks DL, Sypek JP, Vilela L, Gam AA, Evans Davis K. Protective immunity using recombinant human IL 12 and alum as adjuvants in a primate model of cutaneous leishmaniasis. J. Immunol. 163, 4481-4488 (1999).

48 Shankar AH, Titus RG. Leishmania major specific, CD4+, major histocompatibility complex class II restricted T cells derived in vitro from lymphoid tissues of naive mice. J. Exp. Med. 178, 101-111 (1993).

49 Russo DM, Chakrabarti P, Burns JM, Jr. Naive human T cells develop into Thl or Th0 effectors and exhibit cytotoxicity early after stimulation with Leishmania infected macrophages. J. Infect. Dis. 177, 1345-1351 (1998).

50 Pompeu MM, Brodskyn C, Teixeira MJ et al. Differences in $\gamma$ interferon production in vitro predict the pace of the in vivo response to Leishmania amazonensis in healthy volunteers. Infect. Immun. 69 , 7453-7460 (2001).

This paper shows the potential of IVP in the screening of many Leishmania antigens in human cells and therefore, predict potential candidates for a vaccine

51 Veras P, Brodskyn C, Balestieri F et al. A (dhfr ts ) Leishmania major knockout mutant cross protects against Leishmania amazonensis. Mem. Inst. Oswaldo Cruz 94, 491-496 (1999).

52 Brodskyn C, Beverley SM, Titus RG. Virulent or avirulent (dhfr ts ) Leishmania major elicit predominantly a type 1 cytokine response by human cells in vitro. Clin. Exp. Immunol. 119, 299-304 (2000).

53 Alexander J, Coombs GH, Mottram JC. Leishmania mexicana cysteine proteinase deficient mutants have attenuated virulence for mice and potentiate a Th1 response. $J$. Immunol. 161, 6794-6801 (1998).

54 Metz DP, Bottomly K. Function and regulation of memory CD4 $\mathrm{T}$ cells. Immunol. Res. 19, 127-141 (1999).

55 Bretscher PA, Ogunremi O, Menon JN. Distinct immunological states in murine cutaneous leishmaniasis by immunising with different amounts of antigen: the generation of beneficial, potentially harmful, harmful and potentially extremely harmful states. Behring Inst. Mitt. 153-159 (1997).
56 Spitzer N, Jardim A, Lippert D, Olafson RW. Long term protection of mice against Leishmania major with a synthetic peptide vaccine. Vaccine 17, 1298-1300 (1999).

57 Mendez S, Gurunathan S, Kamhawi S et al. The potency and durability of DNA and protein based vaccines against Leishmania major evaluated using low dose, intradermal challenge. J. Immunol. 166, 5122-5128 (2001).

58 Gurunathan S, Prussin C, Sacks DL, Seder RA. Vaccine requirements for sustained cellular immunity to an intracellular parasitic infection. Nat. Med. 4, 1409-1415 (1998).

59 Gurunathan S, Wu CY, Freidag BL, Seder RA. DNA vaccines: a key for inducing long term cellular immunity. Curr. Opin. Immunol. 12, 442-447 (2000).

In these papers, the authors demonstrate that vaccination with plasmid DNA encoding a specific leishmanial antigen is more effective than immunization with leishmanial protein plus recombinant IL 12 in eliciting long term immunity.

60 McMahon Pratt D, Rodriguez D, Rodriguez JR et al. Recombinant vaccinia viruses expressing GP46/M 2 protect against Leishmania infection. Infect. Immun. 61, 3351-3359 (1993).

61 Ramiro MJ, Zarate JJ, Hanke T et al. Protection in dogs against visceral leishmaniasis caused by Leishmania infantum is achieved by immunization with a heterologous prime boost regime using DNA and vaccinia recombinant vectors expressing LACK. Vaccine 21, 2474-2484 (2003).

62 Campos Neto A, Webb JR, Greeson K, Coler RN, Skeiky YA, Reed SG. Vaccination with plasmid DNA encoding TSA/LmSTI1 leishmanial fusion proteins confers protection against Leishmania major infection in susceptible BALB/c mice. Infect. Immun. 70, 2828-2836 (2002).

63 Rafati S, Salmanian AH, Taheri T, Vafa M, Fasel N. A protective cocktail vaccine against murine cutaneous leishmaniasis with DNA encoding cysteine proteinases of Leishmania major. Vaccine 19, 3369-3375 (2001).

64 Mendez S, Belkaid Y, Seder RA, Sacks D. Optimization of DNA vaccination against cutaneous leishmaniasis. Vaccine 20, 3702-3708 (2002).

65 Lopez Fuertes L, Perez Jimenez E, Vila Coro AJ et al. DNA vaccination with linear minimalistic (MIDGE) vectors confers protection against Leishmania major infection in mice. Vaccine 21, 247-257 (2002).
The authors demonstrate that MIDGE vectors coding for the LACK antigen confer a highly effective protection against Leishmania infection in susceptible Balb/c mice. This efficacy was greatly improved by the addition of a nuclear localization signal (NLS) peptide to the end of the MIDGE vector. Results demonstrate that MIDGE vectors are a good alternative to plasmid and rVV for immunization.

66 Hartmann G, Weiner GJ, Krieg AM. CpG DNA: a potent signal for growth, activation, and maturation of human dendritic cells. Pro.c Natl. Acad. Sci. US A 96, 9305-9310 (1999).

67 Sparwasser T, Vabulas RM, Villmow B, Lipford GB, Wagner H. Bacterial CpG DNA activates dendritic cells in vivo: $\mathrm{T}$ helper cell independent cytotoxic $\mathrm{T}$ cell responses to soluble proteins. Eur. $J$. Immunol. 30, 3591-3597 (2000).

68 Ballas ZK, Krieg AM, Warren T et al. Divergent therapeutic and immunologic effects of oligodeoxynucleotides with distinct CpG motifs. J. Immunol. 167, 4878-4886 (2001).

69 Cho HJ, Takabayashi K, Cheng PM et al. Immunostimulatory DNA based vaccines induce cytotoxic lymphocyte activity by a T helper cell independent mechanism. $N a t$. Biotechnol. 18, 509-514 (2000).

70 Walker PS, Scharton Kersten T, Krieg AM et al. Immunostimulatory oligodeoxynucleotides promote protective immunity and provide systemic therapy for leishmaniasis via IL 12 and IFN $\gamma$ dependent mechanisms. Proc. Natl. Acad. Sci. USA 96, 6970-6975 (1999).

71 Rhee EG, Mendez S, Shah JA et al. Vaccination with heat killed Leishmania antigen or recombinant leishmanial protein and $\mathrm{CpG}$ oligodeoxynucleotides induces long term memory $\mathrm{CD}^{+}$and $\mathrm{CD} 8^{+} \mathrm{T}$ cell responses and protection against Leishmania major infection. J. Exp. Med. 195, 1565-1573 (2002).

The authors show the possibility to use $\mathrm{CpG}$ as adjuvant in the development of vaccines against Leishmania.

72 Belkaid Y, Kamhawi S, Modi G et al. Development of a natural model of cutaneous leishmaniasis: powerful effects of vector saliva and saliva preexposure on the long term outcome of Leishmania major infection in the mouse ear dermis. J. Exp. Med. 188, 1941-1953 (1998).

73 Kamhawi S. The biological and immunomodulatory properties of sand fly saliva and its role in the establishment of Leishmania infections. Microbes Infect. 2, 1765-1773 (2000). 
74 Kamhawi S, Belkaid Y, Modi G, Rowton E, Sacks D. Protection against cutaneous leishmaniasis resulting from bites of uninfected sand flies. Science 290, 1351-1354 (2000).

75 Belkaid Y, Valenzuela JG, Kamhawi S, Rowton E, Sacks DL, Ribeiro JM. Delayed type hypersensitivity to Phlebotomus papatasi sand fly bite: An adaptive response induced by the fly? Proc. Natl Acad. Sci. USA 97, 6704-6709 (2000).

The authors show the importance of DTH developed against saliva components in conferring protection against Leishmania in a natural model of transmission, using sand flies infected with parasites. Valenzuela JG, Belkaid Y, Garfield MK et al. Toward a defined anti Leishmania vaccine targeting vector antigens: characterization of a protective salivary protein. J. Exp. Med. 194, 331-342 (2001). The authors show the ability to protect afgainst infection with Leishmania plus sand fly saliva, using cDNA coding for a $15 \mathrm{kDA}$ protein present in sand fly saliva.

77 Barral A, Honda E, Caldas A et al Human immune response to sand fly salivary gland antigens: a useful epidemiological marker? Am. J. Trop. Med. Hyg. 62, 740-745 (2000).
78 Gomes RB, Brodskyn C, de Oliveira CI et al. Seroconversion against Lutzomyia longipalpis saliva concurrent with the development of anti Leishmania chagasi delayed type hypersensitivity. J. Infect. Dis. 186, 1530-1534 (2002).

Demonstrates that in an endemic area for VL, individuals that present anti saliva antibodies develop a DTH against Leishmania and therefore, they would be protected against the infection.

79 Charlab R, Valenzuela JG, Rowton ED, Ribeiro JM. Toward an understanding of the biochemical and pharmacological complexity of the saliva of a hematophagous sand fly Lutzomyia longipalpis. Proc. Nat. Acad. Sci. USA 96, 15155-15160 (1999).

80 Reed SG. Leishmaniasis vaccination: targeting the source of infection. J. Exp. Med. 194, F7-F9 (2001).

\section{Website}

101 www.who.int/emc/diseases/leish The website of the world health organization (WHO). Communicable disease surveillance and response (CSR) unit: surveillance and control of leishmaniasis.
Affiliations

- Claudia Ida Brodskyn, Associate Investigator Instituto de Ciencias da Saude- Universidade Federal da Bahia, Salvador, Bahia, Brazil Centro de Pesquisa Goncalo Moniz - Fundacao Oswaldo Cruz, Salvador, Bahia, Brazil Tel.: +55713568782 , Ext. 211 Fax: +55713568782, Ext. 269 brodskyn@cpqgm.fiocruz.br

- Camila I de Oliveira, Post doctoral fellow Centro de Pesquisa Goncalo Moniz-Fundacao Oswaldo Cruz, Salvador, Bahia, Brazil Tel.: +55713568782 , Ext. 211, Fax: 55713568782, Ext. 269 camila@cpqgm.fiocruz.br

- Aldina Barral Faculdade de Medicina. Universidade Federal da Bahia, Salvador, Bahia, Brazil

Chief of Laboratory of Immunoparasitology, Centro de Pesquisa Goncalo Moniz-Fundacao Oswaldo Cruz, Salvador, Bahia, Brazil Tel.: +55 71 3568782, Ext. 211, Fax: +55713568782 , Ext. 269 abarral@cpqgm.fiocruz.br

- Manoel Barral-Netto Faculdade de Medicina, Universidade Federal da Bahia Salvador Bahia, Brazil

Chief of Laboratory of Immunoregulation, Centro de Pesquisa Goncalo Moniz-Fundacao Oswaldo Cruz, Salvador, Bahia, Brazil Tel.: +55713568782, Ext. 211, Fax: +55713568782 , Ext. 269, mbarral@cpqgm.fiocruz.br 